BMJ Open Diabetes Research \& Care

\section{High prevalence of impaired awareness of hypoglycemia and severe hypoglycemia among people with insulin-treated type 2 diabetes: The Dutch Diabetes Pearl Cohort}

To cite: van Meijel LA, de Vegt F, Abbink EJ, et al. High prevalence of impaired awareness of hypoglycemia and severe hypoglycemia among people with insulintreated type 2 diabetes: The Dutch Diabetes Pearl Cohort. BMJ Open Diab Res Care 2020;8:e000935. doi:10.1136/ bmjdrc-2019-000935

- Additional material is published online only. To view please visit the journal online (http://dx.doi.org/10.1136/ bmjdrc-2019-000935).

Part of the results of this study have been presented at the 78th Scientific Sessions of the American Diabetes Association, Orlando, FL, 22-26 June 2018.

Received 27 September 2019 Revised 3 December 2019 Accepted 15 December 2019

Check for updates

(C) Author(s) (or their employer(s)) 2020. Re-use permitted under CC BY-NC. No commercial re-use. See rights and permissions. Published by BMJ.

For numbered affiliations see end of article.

Correspondence to Dr Lian A van Meijel; Lian.vanMeijel@radboudumc.nl

\section{ABSTRACT}

Objective People with type 2 diabetes on insulin are at risk for hypoglycemia. Recurrent hypoglycemia can cause impaired awareness of hypoglycemia (IAH), and increase the risk for severe hypoglycemia. The aim of this study was to assess the prevalence and determinants of self-reported $\mathrm{IAH}$ and severe hypoglycemia in a Dutch nationwide cohort of people with insulin-treated type 2 diabetes.

Research design and methods Observational study of The Dutch Diabetes Pearl, a cohort of people with type 2 diabetes treated in primary, secondary and tertiary diabetes care centers. The presence of IAH and the occurrence of severe hypoglycemia in the past year, defined as an event requiring external help to recover, were assessed using the validated Dutch version of the Clarke questionnaire. In addition, clinical variables were collected including age, diabetes duration, hemoglobin A1c, ethnicity and education.

Results 2350 people with type 2 diabetes on insulin were included: $59.1 \%$ men, mean age $61.1 \pm 10.4$ years, mean diabetes duration $14.8 \pm 9.2$ years and $79.5 \%$ on basal-bolus therapy. A total of 229 patients $(9.7 \%)$ were classified as having IAH and 742 patients (31.6\%) reported severe hypoglycemia. Increased odds for IAH were found with complex insulin regimens and lower odds with having a partner and body mass index $\geq 30 \mathrm{~kg} /$ $\mathrm{m}^{2}$. Severe hypoglycemia was associated with complex insulin regimens, non-Caucasian ethnicity and use of psychoactive drugs, and inversely with metformin use. Conclusions In this nationwide cohort, almost one out of ten people with type 2 diabetes on insulin had IAH and $>30 \%$ had a history of severe hypoglycemia in the past year.

\section{INTRODUCTION}

Insulin-related hypoglycemia is a common adverse effect of insulin therapy. Recent data show almost 98000 visits to the emergency department and 30000 hospitalizations in the

\section{Significance of this study}

What is already known about this subject?

- Use of insulin therapy in patients with type 2 diabetes creates a risk of developing (severe) hypoglycemia.

- Recurrent (severe) hypoglycemia may lead to the development of impaired awareness of hypoglycemia (IAH).

- The prevalence of IAH in patients with type 1 diabetes is around $25 \%$; however, less is known about the prevalence of IAH in people with type 2 diabetes.

What are the new findings?

- In this nationwide cohort, the prevalence of IAH in patients with type 2 diabetes on insulin therapy was almost $10 \%$.

- The prevalence of severe hypoglycemia in this cohort was more than $30 \%$.

- IAH and severe hypoglycemia occur in patients irrespective of whether they are managed in primary care or not.

How might these results change the focus of research or clinical practice?

- Greater awareness for IAH and severe hypoglycemia in people with type 2 diabetes on insulin is needed.

- Appropriate education to reduce the risk of hypoglycemia in these patients seems warranted

USA per year due to insulin-related hypoglycemia. ${ }^{1}$ Over $75 \%$ of these emergency department visits occur in middle-aged or elderly people, suggesting that most of these people suffer from type 2 diabetes.

The reported prevalence of hypoglycemic events in people with type 2 diabetes on insulin therapy is highly variable and partly determined by the duration and intensity of 


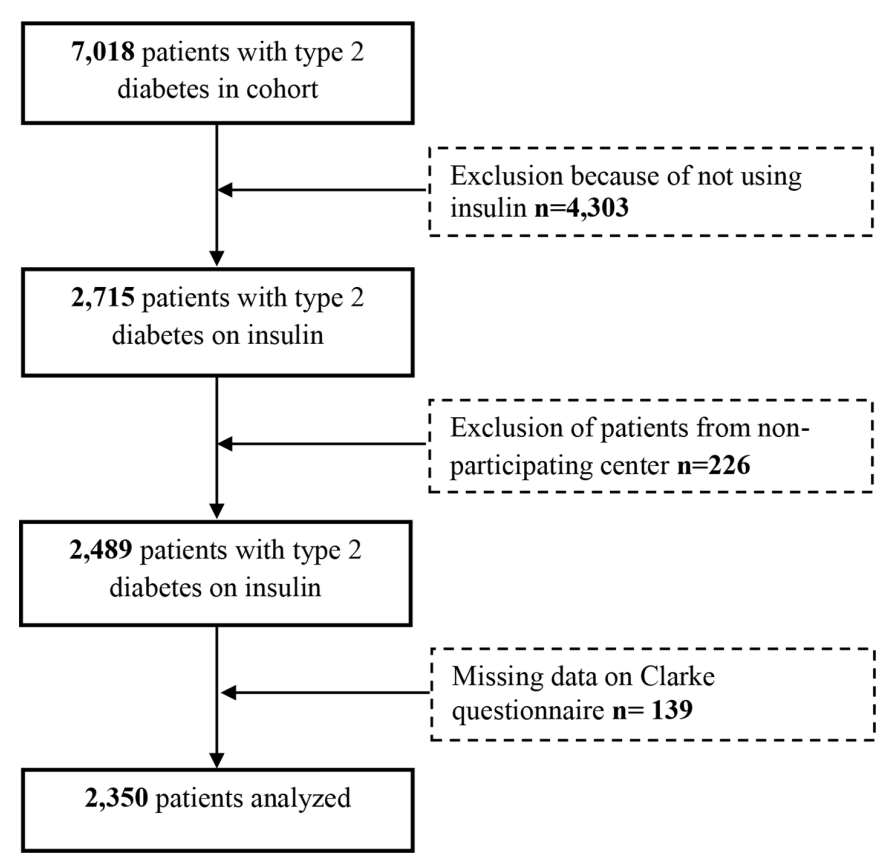

Figure 1 Flow diagram showing patient selection.

insulin therapy. Previous studies have shown that people with type 2 diabetes treated with insulin for $<2$ years experience on average four non-severe episodes per personyear, whereas those treated for $>5$ years experience 10 episodes per person-year. ${ }^{2}{ }^{3}$ Similarly, severe hypoglycemia, defined as an event requiring external help to recover, rarely occurs in the first years after the start of insulin therapy but becomes more common during later years. ${ }^{45}$ One report estimated the overall prevalence of severe hypoglycemia in type 2 diabetes treated with insulin in secondary care at 0.28 episodes per patient per year. $^{6}$

Recurrent exposure to hypoglycemia can induce a process of habituation leading to impaired awareness of hypoglycemia (IAH). This syndrome increases the risk for developing severe hypoglycemia considerably, ${ }^{56}$ yet reflects a functional defect that can be reversed by strict avoidance of hypoglycemia. ${ }^{7-9}$ IAH has been well described in type 1 diabetes and affects approximately $25 \%$ of people with type 1 diabetes, a percentage that appears relatively stable across different cohorts and over time. ${ }^{10-12}$ Less information is available concerning the prevalence of IAH in type 2 diabetes, with reported prevalence of IAH in single-centre surveys varying between $7 \%$ and $46 \%$ among those treated with insulin..$^{5}{ }^{13-15}$ The aim of this study was to assess the prevalence and determinants of IAH and severe hypoglycemia in a large nationwide cohort of patients with insulin-treated type 2 diabetes.

\section{RESEARCH DESIGN AND METHODS}

\section{Study design}

The Dutch Diabetes Pearl is an observational cohort study of people with type 2 diabetes in the Netherlands. The participants are managed in primary care (in the Hoorn area or the region of Maastricht) or in secondary and tertiary care in seven of the total eight academic medical centers across the country. Details on the design of the Dutch Diabetes Pearl have been published previously. ${ }^{16}$ The study was approved by Institutional Review Boards of all the participating medical centers. Patients were excluded if they were unable to understand and write the Dutch language.

\section{Study population}

Patients were enrolled in the Dutch Diabetes Pearl cohort between 2009 and 2015. ${ }^{16}$ For this analysis, we only included patients with type 2 diabetes who were treated with insulin. We excluded patients that did not fill in the Clarke questionnaire, including all participants from one center that did not administer this questionnaire (figure 1).

\section{Study procedure}

After signing informed consent, data were collected following standard operational procedures. Briefly, we collected the following data in the Diabetes Pearl: demographics, physical examinations, laboratory measurements and several questionnaires including the validated Dutch version of the Clarke questionnaire (see below for details). ${ }^{16}$

\section{Study outcomes}

The primary outcome of this study was the prevalence of IAH in people with type 2 diabetes on insulin therapy. All participants were therefore asked to complete the clamp-validated Dutch modified translation of the Clarke questionnaire. ${ }^{17} 18$ This questionnaire consists of a validated translation of the original five questions; two questions on symptoms of hypoglycemia, one on the ability to recognize hypoglycemia based on symptoms, one on the level of blood glucose when experiencing hypoglycemic symptoms, and two questions on the occurrence of severe hypoglycemia, one relating to the requirement of a third party, one relating to the need for medical assistance, both in the past year. Each question was awarded with one or zero points, with three or more out of five points indicating IAH. Severe hypoglycemia was defined by a positive answer to one of both questions regarding severe hypoglycemia. Missing data on the Clarke questionnaire were imputed with 0 (having no symptoms) if patients filled in at least one answer.

\section{Other measurements}

We also assessed a range of demographic and clinical factors including age, diabetes duration, hemoglobin Alc $\left(\mathrm{HbA}_{1 \mathrm{c}}\right)$, ethnicity, smoking, alcohol consumption, having a partner and level of education, to identify potential risk factors, as described below.

Hospital information systems at all recruitment centers were used to collect information on date of birth and gender. Ethnicity was estimated as described earlier. ${ }^{19}$ Education level was self-reported. A high educational level was defined as higher professional education or 
university education. Information on alcohol consumption and smoking were obtained by questionnaire; smoking was categorized as never, former and current smoking. Body mass index (BMI) was defined as a person's weight (kilograms) divided by square of height (meters). Participants brought all their medication or a list from the pharmacy to the hospital so that medication use (eg, beta-blockers and psychoactive drugs) could be reported accurately. Drug use was divided into three arbitrary categories; no polypharmacy (0-4 drugs), moderate polypharmacy (5-9 drugs) and pronounced polypharmacy ( $\geq 10$ drugs). The insulin regimen was categorized as basal only if it consisted of a long-acting insulin analogue or intermediate-acting insulin (ie, NPH (Neutral Protamine Hagedorn) insulin) alone, as pre-mixed if it consisted of pre-mixed insulins, and as basal-bolus (complex insulin regimen) if it consisted of a combination of long-acting or intermediate-acting insulin with short-acting insulin. The latter two regimens were considered 'complex' for the logistic regression analysis (see below). History of cardiovascular disease was defined as at least one of the following events having occurred: acute myocardial infarction, cerebrovascular event, transient ischemic attack and peripheral artery disease. Information on prior cardiovascular disease was assessed by the Rose questionnaire. ${ }^{20} \mathrm{HbA}_{1 \mathrm{c}}$ was reported according to the International Federation of Clinical Chemistry and Laboratory Medicine standard. ${ }^{21}$ Tight glycemic control was defined as $\mathrm{HbA}_{1 \mathrm{c}}<7 \%$ (53 mmol/ $\mathrm{mol})$. All measurements took place in certified on-site laboratories. ${ }^{16}$

\section{Statistical analysis}

Data were analyzed using IBM SPSS statistics V.25. Baseline descriptive analyses were expressed as mean $\pm \mathrm{SD}$, proportion or median (25th and 75th percentiles). Student's independent two-sample t-tests and Pearson's $\chi^{2}$ tests were performed to examine differences between groups. We performed logistic regression analyses to examine the association between several demographic and clinical variables and IAH and severe hypoglycemia. The regression model for IAH and severe hypoglycemia were cumulatively adjusted for age, sex, diabetes duration, $\mathrm{HbA}_{1 \mathrm{c}}$, and for other variables that were significantly associated with the outcome in the crude analysis. A p value of $<0.05$ was considered statistically significant.

\section{RESULTS}

The Diabetes Pearl cohort consists of 7018 individuals. ${ }^{16}$ After excluding participants who were not using insulin $(n=4303)$ did not complete the Clarke questionnaire $(n=226)$ or had too many missing data on the questionnaire $(n=139)$, we included a total of 2350 patients with type 2 diabetes (figure 1 ). There were $59.1 \%$ male participants, mean age was $61.1 \pm 10.4$ years, mean diabetes duration $14.8 \pm 9.2$ years and mean $\mathrm{HbA}_{1 c} 7.9 \% \pm 1.4 \%$
$(62.5 \pm 14.8 \mathrm{mmol} / \mathrm{mol})$. Almost $80 \%$ were on a complex insulin regimen (online supplementary table S1).

\section{Impaired awareness of hypoglycemia}

The distribution of the modified Clarke score was highly skewed (online supplementary figure S1), with a total of 229 individuals $(9.7 \%)$ having a score of $\geq 3$ points, classifying them as having IAH. Clinical characteristics of the individuals with and without IAH are shown in table 1. There were no significant differences in the prevalence of IAH between men and women (10.2 vs $9.1 \%, \mathrm{p}=\mathrm{NS}$ ) and between patients managed in primary or secondary/ tertiary care (8.2 vs $10.4 \%, \mathrm{p}=\mathrm{NS})$. Although glycemic control did not differ between individuals with or without IAH, the prevalence of IAH was significantly higher among individuals with tight glycemic control as compared with those with glycemic control that was less tight $(\mathrm{p}=0.046)$ (figure 2, top). The presence of IAH was associated with complex insulin regimens, non-Caucasian ethnicity, lower BMI and not having a partner, and inversely with the use of sulfonylureas. After multivariate adjustment, complex insulin regimens, not having a partner and lower BMI were still associated with IAH (table 2). There were no statistical differences between the two groups concerning smoking, alcohol consumption, diabetes duration and use of beta-blockers or psychoactive drugs.

\section{Severe hypoglycemia}

Severe hypoglycemia in the past 12 months was reported by 742 patients $(31.6 \%), 193(8.2 \%)$ of whom required medical intervention. The prevalence of severe hypoglycemia was similar across sex, but significantly higher among those with poorer glycemic control $(\mathrm{p}=0.016)$ (figure 2, bottom). People with a history of severe hypoglycemia were more often non-Caucasian, had a longer diabetes duration, had a history of cardiovascular events, used psychoactive drugs and reported pronounced polypharmacy (table 1). Furthermore, people with severe hypoglycemia were more likely to use complex insulin regimens and less likely to use sulfonylureas or metformin, and were more often seen in secondary/ tertiary care than in primary care centers when compared with people without severe hypoglycemia. However, after multivariate adjustment, the level of care was no longer associated with severe hypoglycemia and the same was true for use of sulfonylureas, pronounced polypharmacy and history of cardiovascular disease (table 3 ).

\section{CONCLUSIONS}

In this nationwide cohort of patients with type 2 diabetes treated with insulin, we found that the prevalence of IAH was $9.7 \%$ and that almost one out of three individuals reportedly experienced a severe hypoglycemic event in the preceding year. We observed that people not having a partner, with more complex insulin treatment regimens, use of psychoactive drugs, BMI $<30 \mathrm{~kg} / \mathrm{m}^{2}$ and non-Caucasian descent were more susceptible for IAH or severe hypoglycemia. Interestingly, tight glycemic control 
Table 1 Clinical characteristics of people $(\mathrm{n}=2350)$ with or without IAH and severe hypoglycemia

\begin{tabular}{|c|c|c|c|c|}
\hline Characteristic & IAH $(n=229)$ & No IAH $(n=2121)$ & $\begin{array}{l}\text { Severe hypoglycemia } \\
(\mathrm{n}=742)\end{array}$ & $\begin{array}{l}\text { No severe } \\
\text { hypoglycemia }(n=1608)\end{array}$ \\
\hline Sex (male) & $142(62.0)$ & $1248(58.8)$ & 437 (58.9) & 953 (59.3) \\
\hline Age (years) & $59.9 \pm 11.0$ & $61.2 \pm 10.3$ & $60.8 \pm 10.5$ & $61.2 \pm 10.3$ \\
\hline \multicolumn{5}{|l|}{ Clinical care } \\
\hline Primary care & $55(24.0)$ & $614(28.9)$ & $185(25.1)^{\star}$ & $484(30.2)$ \\
\hline $\begin{array}{l}\text { Secondary/tertiary } \\
\text { care }\end{array}$ & $173(75.5)$ & $1497(70.6)$ & $551(74.9)^{\star}$ & $1119(69.8)$ \\
\hline $\begin{array}{l}\text { Diabetes duration } \\
\text { (years) }\end{array}$ & $15.5 \pm 9.7$ & $14.7 \pm 9.1$ & $15.7 \pm 9.4^{*}$ & $14.3 \pm 9.0$ \\
\hline $\mathrm{HbA}_{1 \mathrm{c}}(\%)(\mathrm{mmol} / \mathrm{mol})$ & $7.8 \pm 1.4(61.4 \pm 15.3)$ & $7.9 \pm 1.3(62.6 \pm 14.7)$ & $8.0 \pm 1.4(63.7 \pm 15.5)$ & $7.8 \pm 1.3(62.0 \pm 14.4)$ \\
\hline \multicolumn{5}{|l|}{ Insulin treatment } \\
\hline Basal only & $25(10.9) \dagger$ & $453(21.4)$ & $106(14.3)^{\star}$ & $372(23.1)$ \\
\hline Pre-mixed & 40 (17.5) & 339 (16.0) & $122(16.4)$ & $257(16.0)$ \\
\hline Basal-bolus & $163(71.2) \dagger$ & $1327(62.6)$ & $513(69.1)^{\star}$ & $977(60.8)$ \\
\hline Use of sulfonylureas & $12(5.2) \dagger$ & $240(11.3)$ & $59(8.0)^{\star}$ & $193(12.0)$ \\
\hline Use of metformin & $128(55.9)$ & $1324(62.4)$ & $423(57.0)^{\star}$ & $1029(64.0)$ \\
\hline $\begin{array}{l}\text { Pronounced } \\
\text { polypharmacy }\end{array}$ & 73 (31.9) & $632(29.8)$ & $263(35.4)^{\star}$ & $442(27.5)$ \\
\hline Beta-blocker use & $86(37.6)$ & $859(40.5)$ & 298 (40.2) & 647 (40.2) \\
\hline $\begin{array}{l}\text { Psychoactive drug } \\
\text { use }\end{array}$ & $52(22.7)$ & $477(22.5)$ & $209(28.2)^{\star}$ & 320 (19.9) \\
\hline Ethnicity (Caucasian) & $169(75.4) \dagger$ & $1714(81.5)$ & $565(77.2)^{\star}$ & $1318(82.6)$ \\
\hline Partner (yes) & $122(63.2) \dagger$ & $1301(73.5)$ & $443(72.0)$ & $980(72.7)$ \\
\hline $\begin{array}{l}\text { High educational } \\
\text { level (yes) }\end{array}$ & $54(23.8)$ & 499 (23.6) & $159(21.6)$ & $394(24.6)$ \\
\hline Current smoker (yes) & $47(20.6)$ & $389(18.4)$ & 145 (19.6) & 291 (18.2) \\
\hline $\begin{array}{l}\text { High alcohol } \\
\text { consumption ( } \geq 14 \\
\text { glasses/week) }\end{array}$ & $15(6.6)$ & $132(6.3)$ & $49(6.7)$ & $98(6.2)$ \\
\hline $\mathrm{BMI} \geq 30\left(\mathrm{~kg} / \mathrm{m}^{2}\right)$ & $112(49.3) \dagger$ & $1198(57.3)$ & $410(55.8)$ & $900(56.9)$ \\
\hline $\begin{array}{l}\text { History of } \\
\text { cardiovascular } \\
\text { disease (yes) }\end{array}$ & $81(35.4)$ & $645(30.4)$ & $261(35.2)^{*}$ & 465 (28.9) \\
\hline
\end{tabular}

Data are shown as number (\%) or mean \pm SD. History of cardiovascular disease was defined as having $\geq 1$ of the following; acute myocardial infarction, cerebrovascular event, transient ischemic attack, peripheral artery disease. Pronounced polypharmacy was defined as using $\geq 10$ drugs.

${ }^{*} \mathrm{p}<0.05$ versus no $\mathrm{SH}$.

$\dagger \mathrm{p}<0.05$ versus no IAH

$\mathrm{BMI}$, body mass index; IAH, impaired awareness of hypoglycemia; $\mathrm{SH}$, severe hypoglycemia.

was associated with a higher prevalence of IAH, but at the same time with a lower risk of severe hypoglycemia. Furthermore, the prevalence of severe hypoglycemia was significantly higher in secondary/tertiary care, but the association between level of care and severe hypoglycemia was no longer statistically significant after multivariate adjustment.

Our data on the prevalence of IAH in people with insulin-treated type 2 diabetes are in line with those reported in small studies using either the Gold score ${ }^{613}$ or the Clarke questionnaire, ${ }^{22}$ and extend these to a more general population of people with type 2 diabetes on insulin, including those from primary care. In accordance with previous findings, participants with IAH had somewhat tighter and those with severe hypoglycemia had somewhat poorer metabolic control. ${ }^{132324}$ Our data contrast with single-center surveys from Denmark ${ }^{514}$ and Turkey ${ }^{25}$ that reported IAH to vary between $31 \%$ and even $94 \%$ among people with type 2 diabetes on insulin. Part of this discrepancy may result from differences between questionnaires, thus potentially identifying different subgroups. We used the Dutch modified version of the Clarke questionnaire, which has been validated against hypoglycemic clamps in people with type 1 diabetes. ${ }^{17}$ 

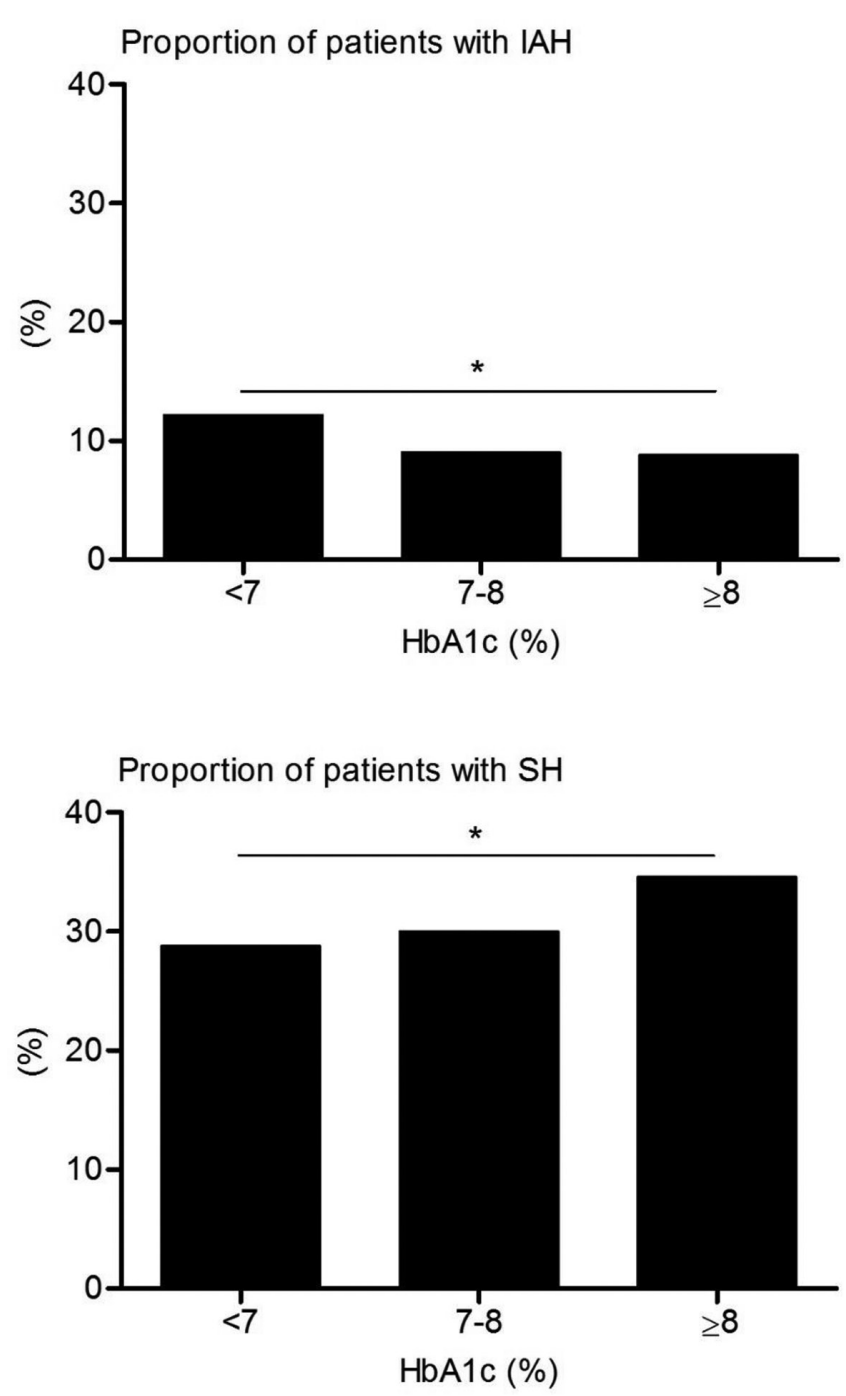

Figure 2 Proportion (\%) of patients with IAH (top) or severe hypoglycemia (SH) (bottom) according to glycemic category, $7 \%=53 \mathrm{mmol} / \mathrm{mol}, 8 \%=64 \mathrm{mmol} / \mathrm{mol}$, ${ }^{\star} \mathrm{P}$ value for trend $<0.05$. $\mathrm{IAH}$, impaired awareness of hypoglycemia.

The methods by Gold and Clarke have a good mutual concordance and good predictability for biochemical hypoglycemia, but correlate less well with the method used in Denmark. ${ }^{26}$ The latter method has been criticized for overestimating the prevalence of IAH. ${ }^{26} 27$

IAH was almost as prevalent in people with type 2 diabetes managed by primary care physicians as in those managed in secondary/tertiary care centers. The prevalence of severe hypoglycemia was slightly higher in secondary/tertiary care when compared with primary care. In fact, the association between type of care and severe hypoglycemia was completely lost after correction for age, sex, diabetes duration and $\mathrm{HbA}_{1 c}$. Conversely, use of a complex insulin regimen increased the risk for both IAH and severe hypoglycemia, which was independent of where they received their care. The size and diversity of our cohort enabled us to also uncover non-Caucasian ethnicity and having no partner as independent new determinants of severe hypoglycemia and IAH, respectively, in people with type 2 diabetes, whereas we found no evidence for associations with smoking, as reported previously. ${ }^{23}$

Use of metformin was independently associated with lower odds of severe hypoglycemia in our population, which corroborates findings of a recent large cohort study. ${ }^{28}$ The underlying mechanism explaining this observation remains to be determined. Metformin has been shown to modestly enhance the release of growth hormone during hypoglycemia, but not that of other counterregulatory hormones. ${ }^{29}$ Alternatively, metformininduced increases in plasma lactate may preserve brain function during hypoglycemia, thus potentially providing protection against severe hypoglycemia. ${ }^{30}{ }^{31}$ In univariate analysis, we also found an inverse relationship between use of sulfonylureas and IAH or severe hypoglycemia. Since particularly long-acting sulfonylureas are associated with increased risks of hypoglycemia, ${ }^{32}{ }^{33}$ this seemingly paradoxical finding is best explained by reverse causality. Indeed, it is highly likely that sulfonylureas were stopped after intensifying insulin therapy, in accordance with international guidelines, ${ }^{34}$ or after experiencing severe or frequent hypoglycemic events, and not even commenced in patients thought to be at increased risk of hypoglycemia.

\begin{tabular}{|c|c|c|c|c|}
\hline Variable & $\begin{array}{l}\text { OR }(95 \% \mathrm{Cl}) \\
\text { Crude analysis }\end{array}$ & $\begin{array}{l}\text { OR }(95 \% \text { Cl) } \\
\text { Model } 1\end{array}$ & $\begin{array}{l}\text { OR }(95 \% \text { Cl) } \\
\text { Model } 2\end{array}$ & $\begin{array}{l}\text { OR }(95 \% \text { Cl) } \\
\text { Model } 3\end{array}$ \\
\hline Caucasian ethnicity & $0.70(0.51-0.97)$ & $0.73(0.52-1.02)$ & $0.69(0.48-0.99)$ & $0.76(0.52-1.12)$ \\
\hline Having a partner & $0.62(0.45-0.85)$ & $0.60(0.44-0.82)$ & $0.59(0.42-0.82)$ & $0.59(0.42-0.84)$ \\
\hline $\mathrm{BMI} \geq 30 \mathrm{~kg} / \mathrm{m}^{2}$ & $0.73(0.55-0.95)$ & $0.72(0.55-0.95)$ & $0.78(0.58-1.06)$ & $0.71(0.51-0.98)$ \\
\hline Complex insulin regimen & $2.21(1.44-3.39)$ & $2.20(1.43-3.38)$ & $2.01(1.29-3.16)$ & $1.75(1.06-2.88)$ \\
\hline Use of sulfonylureas & $0.43(0.24-0.79)$ & $0.44(0.24-0.81)$ & $0.47(0.25-0.88)$ & $0.62(0.30-1.26)$ \\
\hline
\end{tabular}

Statistically significant data $(\mathrm{p}<0.05)$ appear in boldface type. Model 1 is adjusted for age and sex. Model 2 is adjusted for age, sex, $\mathrm{HbA}_{1 \mathrm{c}}$ and diabetes duration. Model 3 is adjusted for age, sex, $\mathrm{HbA}_{1 \mathrm{c}}$ and diabetes duration and for all other variables mentioned in table 2. Complex insulin regimen: a regimen consisting of pre-mixed insulin or combination of short-acting and intermediate-acting or long-acting insulin.

$\mathrm{BMI}$, body mass index ; IAH, impaired awareness of hypoglycemia. 


(1)

Table 3 Logistic regression analyses to assess the association between variables and severe hypoglycemia in people with type 2 diabetes on insulin

\begin{tabular}{|c|c|c|c|c|}
\hline Variable & $\begin{array}{l}\text { OR }(95 \% \mathrm{Cl}) \\
\text { Crude analysis }\end{array}$ & $\begin{array}{l}\text { OR }(95 \% \text { Cl) } \\
\text { Model } 1\end{array}$ & $\begin{array}{l}\text { OR (95\% Cl) } \\
\text { Model } 2\end{array}$ & $\begin{array}{l}\text { OR (95\% Cl) } \\
\text { Model } 3\end{array}$ \\
\hline Caucasian ethnicity & $0.72(0.58-0.89)$ & $0.72(0.58-0.90)$ & $0.75(0.60-0.96)$ & $0.69(0.54-0.88)$ \\
\hline Clinical care (secondary/tertiary) & $1.29(1.06-1.57)$ & $1.28(1.05-1.56)$ & $1.16(0.93-1.44)$ & $0.92(0.72-1.16)$ \\
\hline Complex insulin regimen & $1.81(1.43-2.29)$ & $1.80(1.42-2.28)$ & $1.64(1.27-2.12)$ & $1.44(1.07-1.94)$ \\
\hline Use of sulfonylureas & $0.63(0.47-0.86)$ & $0.64(0.47-0.87)$ & $0.68(0.50-0.95)$ & $0.88(0.60-1.27)$ \\
\hline Use of metformin & $0.75(0.63-0.89)$ & $0.74(0.62-0.88)$ & $0.75(0.62-0.91)$ & $0.76(0.62-0.93)$ \\
\hline Pronounced polypharmacy & $1.45(1.20-1.75)$ & $1.48(1.22-1.78)$ & $1.40(1.15-1.71)$ & $1.22(0.97-1.54)$ \\
\hline Use of psychoactive drugs & $1.58(1.29-1.93)$ & $1.58(1.29-1.94)$ & $1.54(1.24-1.91)$ & $1.37(1.08-1.75)$ \\
\hline History of cardiovascular disease & $1.33(1.11-1.61)$ & $1.37(1.13-1.65)$ & $1.26(1.03-1.54)$ & $1.17(0.95-1.45)$ \\
\hline
\end{tabular}

Statistically significant data $(\mathrm{p}<0.05)$ appear in boldface type. Model 1 is adjusted for age and sex. Model 2 is adjusted for age, sex, $\mathrm{HbA}_{1 \mathrm{c}}$ and diabetes duration. Model 3 is adjusted for age, sex, $\mathrm{HbA}_{1}$, diabetes duration and diabetes duration and for all other variables mentioned in table 2. Complex insulin regimen: a regimen consisting of pre-mixed insulin or combination of short-acting and intermediate- or longacting insulin.

Our study has clinical implications as it shows that both IAH and severe hypoglycemia are common in people with type 2 diabetes on insulin therapy, even in those using basal insulin therapy alone or managed in primary care. Remarkably, although the prevalence of IAH in type 2 diabetes is at least twofold lower than what has been reported in type 1 diabetes, the occurrence of severe hypoglycemia was at least of the same magnitude. ${ }^{10113536}$ A lack in education about hypoglycemia focused on this population may explain at least a part of this discrepancy. The symptomatology of hypoglycemia may differ in elderly people with type 2 diabetes, whereas those with type 1 diabetes are usually younger, have longer experience with insulin treatment and consequently may already have been educated more intensively and more frequently about hypoglycemia. ${ }^{37} 38$ Some other risk factors for IAH in our study, for example non-Caucasian ethnicity, may also be partly explained by an educational gap. Focused education may reduce the burden of hypoglycemia and its potentially harmful consequences (eg, falls), as well as the associated risk of cardiovascular morbidity and mortality. ${ }^{39-41}$

Strengths of our study include the size of the cohort, being the largest to date in which the prevalence of IAH in type 2 diabetes has been determined and its national coverage due to the collaboration of all academic medical centers in the Netherlands. The inclusion of primary, secondary and tertiary care patients and the use of standardized protocols for data collection increase its generalizability. Our study also has limitations. Based on selection by academic centers, there may be an overrepresentation of complicated tertiary care patients. However, it should be noted that most previous studies also collected data in academic centers. ${ }^{6}{ }^{1322}$ Second, the questionnaire we used to estimate IAH has not formally been validated in type 2 diabetes, but this applies to all questionnaires currently used for this purpose. Future research is needed to validate the questionnaire in patients with type 2 diabetes. Finally, we did not measure C-peptide values, the presence of which has been associated with lower hypoglycemia risks in people with type 1 diabetes,${ }^{42}$ and most data were collected before the widespread use of continuous glucose monitoring techniques.

In conclusion, IAH and severe hypoglycemia are relatively common among people with type 2 diabetes treated with insulin, particularly when managed with an intensified regimen, but independent of whether this is applied in primary, secondary or tertiary care. Greater awareness for IAH and severe hypoglycemia in people with type 2 diabetes on insulin is needed, with special attention for people without a partner or with non-Caucasian ethnicities. Appropriate education to reduce the risk of hypoglycemia in people with type 2 diabetes on insulin seems warranted, although this remains to be investigated.

\section{Author affiliations}

${ }^{1}$ Department of Internal Medicine, Radboud University Medical Center, Nijmegen, The Netherlands

${ }^{2}$ Department for Health Evidence, Radboud University Medical Center, Nijmegen, The Netherlands

${ }^{3}$ Department of Epidemiology \& Biostatistics, Amsterdam UMC - Locatie VUMC, Amsterdam, The Netherlands

${ }^{4}$ Department of Medicine, Maastricht University Medical Center (MUMC+), Maastricht, The Netherlands

${ }^{5}$ Department of Endocrinology, University Medical Center Groningen, Groningen, The Netherlands

${ }^{6}$ Department of Internal Medicine, Amsterdam UMC - Locatie AMC, Amsterdam, The Netherlands

${ }^{7}$ Department of Internal Medicine, Erasmus MC, Rotterdam, The Netherlands ${ }^{8}$ Department of Internal Medicine, University Medical Center Utrecht, Utrecht, The Netherlands

${ }^{9}$ Department of General Practice and Elderly Care, Amsterdam Public Health Research Institute, Amsterdam UMC - Locatie VUMC, Amsterdam, The Netherlands

Acknowledgements We thank all the volunteers for their participation in the Dutch Diabetes Pearl cohort. We also thank 0. Dekkers for his feedback on an earlier draft of the manuscript.

Contributors BEDG and CJT designed the study. FdV analyzed the data. LAvM wrote the first draft of the manuscript. LAvM, FdV, EJA, FR, MTS, MMvdK, BHRW, 
SS, JHD, EJGS, BÖ, HWdV, BS, NS, CDAS, PJE, CJT, BEDG critically revised and contributed to the final version of the manuscript. LAvM, FdV, CJT and BEDG. are the guarantors of this work and accept full responsibility for the work and/or the conduct of the study, had access to the data, and controlled the decision to publish. The corresponding author attests that all listed authors meet authorship criteria and that no others meeting the criteria have been omitted.

Funding The initial organization of the Dutch Diabetes Pearl was co-financed by the Dutch Government and the eight Dutch University Medical Centers. The continuation is financed by the Dutch Federation of University Medical Centers. The funding body had no role in designing the study or in collecting, analyzing, or interpreting data, writing of the report or in the decision to submit the article for publication. The research has been conducted fully independent of the funders, and all authors, external and internal, had full access to all of the data (including statistical reports and tables) in the study and can take responsibility for the integrity of the data and the accuracy of the data analysis.

Competing interests FR has received grants from the Dutch government, during the conduct of the study. JHD has received personal fees from Novo Nordisk and Sanofi, outside the submitted work. CJT has received grants from AstraZeneca, personal fees and other from NovoNordisk and from Merck, outside the submitted work. BEDG has received grants from the Dutch Federation of University Medical Centers, during the conduct of the study and personal fees from NovoNordisk, outside the submitted work.

Patient consent for publication Not required.

Provenance and peer review Not commissioned; externally peer reviewed.

Data availability statement All data relevant to the study are included in the article or uploaded as supplementary information.

Open access This is an open access article distributed in accordance with the Creative Commons Attribution Non Commercial (CC BY-NC 4.0) license, which permits others to distribute, remix, adapt, build upon this work non-commercially, and license their derivative works on different terms, provided the original work is properly cited, appropriate credit is given, any changes made indicated, and the use is non-commercial. See: http://creativecommons.org/licenses/by-nc/4.0/.

ORCID iDs

Lian A van Meijel http://orcid.org/0000-0001-6579-8488

Miranda T Schram http://orcid.org/0000-0001-8113-7604

Cornelis J Tack http://orcid.org/0000-0003-0322-1653

Bastiaan E de Galan http://orcid.org/0000-0002-1255-7741

\section{REFERENCES}

1 Geller Al, Shehab N, Lovegrove MC, et al. National estimates of insulin-related hypoglycemia and errors leading to emergency department visits and hospitalizations. JAMA Intern Med 2014;174:678-86.

2 UK Hypoglycaemia Study Group. Risk of hypoglycaemia in types 1 and 2 diabetes: effects of treatment modalities and their duration. Diabetologia 2007;50:1140-7.

3 Zammitt NN, Frier BM. Hypoglycemia in type 2 diabetes: pathophysiology, frequency, and effects of different treatment modalities. Diabetes Care 2005;28:2948-61.

4 International Hypoglycaemia Study Group. Minimizing hypoglycemia in diabetes. Diabetes Care 2015;38:1583-91.

5 Akram K, Pedersen-Bjergaard U, Carstensen B, et al. Frequency and risk factors of severe hypoglycaemia in insulin-treated type 2 diabetes: a cross-sectional survey. Diabet Med 2006;23:750-6.

6 Henderson JN, Allen KV, Deary IJ, et al. Hypoglycaemia in insulintreated type 2 diabetes: frequency, symptoms and impaired awareness. Diabet Med 2003;20:1016-21.

7 Dagogo-Jack S, Rattarasarn C, Cryer PE. Reversal of hypoglycemia unawareness, but not defective glucose counterregulation, in IDDM. Diabetes 1994;43:1426-34.

8 Fanelli CG, Epifano L, Rambotti AM, et al. Meticulous prevention of hypoglycemia normalizes the glycemic thresholds and magnitude of most of neuroendocrine responses to, symptoms of, and cognitive function during hypoglycemia in intensively treated patients with short-term IDDM. Diabetes 1993;42:1683-9.

9 Cranston I, Lomas J, Maran A, et al. Restoration of hypoglycaemia awareness in patients with long-duration insulin-dependent diabetes. Lancet 1994;344:283-7.

10 Olsen SE, Asvold BO, Frier BM, et al. Hypoglycaemia symptoms and impaired awareness of hypoglycaemia in adults with type 1 diabetes: the association with diabetes duration. Diabet Med 2014;31:1210-7.
11 Geddes J, Schopman JE, Zammitt NN, et al. Prevalence of impaired awareness of hypoglycaemia in adults with type 1 diabetes. Diabetic Med 2008;25:501-4.

12 Graveling AJ, Noyes KJ, Allerhand $\mathrm{MH}$, et al. Prevalence of impaired awareness of hypoglycemia and identification of predictive symptoms in children and adolescents with type 1 diabetes. Pediatr Diabetes 2014;15:206-13.

13 Schopman JE, Geddes J, Frier BM. Prevalence of impaired awareness of hypoglycaemia and frequency of hypoglycaemia in insulin-treated type 2 diabetes. Diabetes Res Clin Pract 2010;87:64-8.

14 Akram K, Pedersen-Bjergaard U, Carstensen B, et al. Prospective and retrospective recording of severe hypoglycaemia, and assessment of hypoglycaemia awareness in insulin-treated type 2 diabetes. Diabet Med 2009;26:1306-8.

15 Hepburn DA, MacLeod KM, Pell AC, et al. Frequency and symptoms of hypoglycaemia experienced by patients with type 2 diabetes treated with insulin. Diabet Med 1993;10:231-7.

16 van't Riet E, Schram MT, Abbink EJ, et al. The diabetes pearl: diabetes biobanking in the Netherlands. BMC Public Health 2012;12:949.

17 Janssen MM, Snoek FJ, Heine RJ. Assessing impaired hypoglycemia awareness in type 1 diabetes: agreement of selfreport but not of field study data with the autonomic symptom threshold during experimental hypoglycemia. Diabetes Care 2000;23:529-32.

18 Clarke WL, Cox DJ, Gonder-Frederick LA, et al. Reduced awareness of hypoglycemia in adults with IDDM. A prospective study of hypoglycemic frequency and associated symptoms. Diabetes Care 1995;18:517-22

19 Özcan B, Rutters F, Snoek FJ, et al. High diabetes distress among ethnic minorities is not explained by metabolic, cardiovascular, or lifestyle factors: findings from the Dutch diabetes pearl cohort. Diabetes Care 2018;41:1854-61.

20 Leng GC, Fowkes FG. The Edinburgh claudication questionnaire: an improved version of the WHO/Rose questionnaire for use in epidemiological surveys. J Clin Epidemiol 1992;45:1101-9.

21 Consensus Committee. Consensus statement on the worldwide standardization of the hemoglobin A1c measurement: the American diabetes association, European association for the study of diabetes, International Federation of clinical chemistry and laboratory medicine, and the International diabetes Federation. Diabetes Care 2007;30:2399-400.

22 Zhu L, Ang LC, Tan WB, et al. A study to evaluate the prevalence of impaired awareness of hypoglycaemia in adults with type 2 diabetes in outpatient clinic in a tertiary care centre in Singapore. Ther Adv Endocrinol Metab 2017;8:69-74.

23 Berlin I, Sachon CI, Grimaldi A. Identification of factors associated with impaired hypoglycaemia awareness in patients with type 1 and type 2 diabetes mellitus. Diabetes Metab 2005;31:246-51.

24 Miller ME, Bonds DE, Gerstein HC, et al. The effects of baseline characteristics, glycaemia treatment approach, and glycated haemoglobin concentration on the risk of severe hypoglycaemia: post hoc epidemiological analysis of the Accord study. BMJ 2010;340:b5444.

25 Büyükkaya Besen D, Arda Sürücü H, Koșar C. Self-Reported frequency, severity of, and awareness of hypoglycemia in type 2 diabetes patients in turkey. PeerJ 2016;4:e2700.

26 Geddes J, Wright RJ, Zammitt NN, et al. An evaluation of methods of assessing impaired awareness of hypoglycemia in type 1 diabetes. Diabetes Care 2007;30:1868-70.

27 Geddes J, Frier BM. Severe hypoglycaemia in insulin-treated type 2 diabetes. Diabet Med 2007;24:327.

28 Misra-Hebert AD, Pantalone KM, Ji X, et al. Patient characteristics associated with severe hypoglycemia in a type 2 diabetes cohort in a large, integrated health care system from 2006 to 2015. Diabetes Care 2018:41:1164-71.

29 Fruehwald-Schultes B, Kern W, Oltmanns KM, et al. Metformin does not adversely affect hormonal and symptomatic responses to recurrent hypoglycemia. J Clin Endocrinol Metab 2001;86:4187-92.

30 Ferrannini E. The target of metformin in type 2 diabetes. N Engl J Med 2014;371:1547-8.

31 Wiegers EC, Rooijackers HM, Tack CJ, et al. Effect of exerciseinduced lactate elevation on brain lactate levels during hypoglycemia in patients with type 1 diabetes and impaired awareness of hypoglycemia. Diabetes 2017;66:3105-10.

32 Intensive blood-glucose control with sulphonylureas or insulin compared with conventional treatment and risk of complications in patients with type 2 diabetes (UKPDS 33). The Lancet 1998;352:837-53. 
33 Cryer PE. Glycemic goals in diabetes: trade-off between glycemic control and iatrogenic hypoglycemia. Diabetes 2014;63:2188-95.

34 Davies MJ, D'Alessio DA, Fradkin J, et al. Management of hyperglycemia in type 2 diabetes, 2018. A consensus report by the American diabetes association (ADA) and the European association for the study of diabetes (EASD). Diabetes Care 2018;41:2669-701.

35 The DCCT Research Group. Epidemiology of severe hypoglycemia in the diabetes control and complications trial. The DCCT Research Group. Am J Med 1991;90:450-9.

36 ter Braak EW, Appelman AM, van de Laak M, et al. Clinical characteristics of type 1 diabetic patients with and without severe hypoglycemia. Diabetes Care 2000;23:1467-71.

37 Jaap AJ, Jones GC, McCrimmon RJ, et al. Perceived symptoms of hypoglycaemia in elderly type 2 diabetic patients treated with insulin. Diabet Med 1998;15:398-401.

38 Bonds DE, Miller ME, Dudl J, et al. Severe hypoglycemia symptoms, antecedent behaviors, immediate consequences and association with glycemia medication usage: secondary analysis of the Accord clinical trial data. BMC Endocr Disord 2012;12:5.

39 Zoungas S, Patel A, Chalmers J, et al. Severe hypoglycemia and risks of vascular events and death. N Engl J Med 2010;363:1410-8.

40 Hsu P-F, Sung S-H, Cheng H-M, et al. Association of clinical symptomatic hypoglycemia with cardiovascular events and total mortality in type 2 diabetes: a nationwide population-based study. Diabetes Care 2013;36:894-900.

41 Khunti K, Davies M, Majeed A, et al. Hypoglycemia and risk of cardiovascular disease and all-cause mortality in insulin-treated people with type 1 and type 2 diabetes: a cohort study. Diabetes Care 2015;38:316-22.

42 Marren SM, Hammersley S, McDonald TJ, et al. Persistent $\mathrm{C}$-peptide is associated with reduced hypoglycaemia but not $\mathrm{HbA}_{1}$ in adults with longstanding Type 1 diabetes: evidence for lack of intensive treatment in UK clinical practice? Diabet Med 2019;36:1092-9. 